\title{
Korean Guideline for the Prevention and Treatment of Glucocorticoid-induced Osteoporosis
}

\author{
So Young Park' , Hyun Sik Gong ${ }^{2}$, Kyoung Min Kim ${ }^{3}$, Dam Kim ${ }^{4}$, Ha Young Kim5, Chan Hong Jeon ${ }^{6}$, Ji Hyeon Ju', \\ Shin-Seok Lee ${ }^{8}$, Dong-Ah Park ${ }^{9}$, Yoon-Kyoung Sung ${ }^{10, *}$, Sang Wan Kim ${ }^{11, *}$ \\ 'Division of Endocrinology and Metabolism, Department of Internal Medicine, Kyung Hee University Hospital, Seoul; \\ ${ }^{2}$ Department of Orthopedic Surgery, Seoul National University Bundang Hospital, Seoul National University College of Medicine, Seongnam; \\ ${ }^{3}$ Division of Endocrinology and Metabolism, Department of Internal Medicine, Seoul National University Bundang Hospital, Seoul National \\ University College of Medicine, Seongnam; \\ ${ }^{4}$ Division of Rheumatology, Department of Internal Medicine, Yonsei University College of Medicine, Seoul; \\ ${ }^{5}$ Division of Endocrinology, Department of Internal Medicine, Wonkwang University Sanbon Hospital, Wonkwang University School of \\ Medicine, Gunpo; \\ ${ }^{6}$ Division of Rheumatology, Department of Internal Medicine, Soonchunhyang University Hospital, Bucheon; \\ ${ }^{7}$ Division of Rheumatology, Department of Internal Medicine, Seoul St. Mary's Hospital, College of Medicine, The Catholic University of \\ Korea, Seoul; \\ ${ }^{8}$ Department of Rheumatology, Chonnam National University Medical School and Hospital, Gwangju; \\ ${ }^{9}$ Division of Healthcare Technology Assessment Research, National Evidence-Based Healthcare Collaborating Agency, Seoul; \\ ${ }^{10}$ Department of Rheumatology, Hanyang University Hospital for Rheumatic Diseases, Seoul; \\ ${ }^{11}$ Division of Endocrinology and Metabolism, Department of Internal Medicine, Seoul National University College of Medicine, Boramae \\ Medical Center, Seoul, Korea
}

\author{
Corresponding author \\ Sang Wan Kim \\ Division of Endocrinology and Metabolism, Department \\ of Internal Medicine, Seoul National University College \\ of Medicine, Boramae Medical Center, 20 Boramae-ro \\ 5-gil, Dongjak-gu, Seoul 07061, Korea \\ Tel: +82-2-870-2223, Fax: +82-2-870-3863 \\ E-mail: swkimmd@snu.ac.kr \\ Yoon-Kyoung Sung \\ Department of Rheumatology, Hanyang University \\ Hospital for Rheumatic Diseases, 222-1 Wangsimni-ro, \\ Seongdong-gu, Seoul 04763, Korea \\ Tel: +82-2-2290-9250, Fax: +82-2-2298-8231 \\ E-mail: sungyk@hanyang.ac.kr \\ Received: July 13, 2018 \\ Revised: August 6, 2018 \\ Accepted: August 10, 2018 \\ *Sang Wan Kim and Yoon-Kyoung Sung contributed equally
to this work and should be considered co-corresponding
authors. \\ These Guideline is being published simultaneously in the \\ Korean Society of Bone and Mineral Metabolism (KSBMR) \\ and Korean College of Rheumatology (KCR).
}

Copyright $\odot 2018$ The Korean Society for Bone and Mineral Research

This is an Open Access article distributed under the terms of the Creative Commons Attribution Non-Commercial License (http://creativecommons.org/licenses/by-nc/4.0/) which permits unrestricted non-commercial use, distribution, and reproduction in any medium, provided the original work is properly cited.

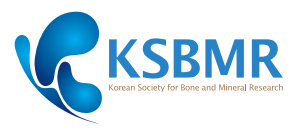

Background: To develop guidelines and recommendations to prevent and treat glucocorticoid (GC)-induced osteoporosis (GIOP) in Korea. Methods: The Korean Society for Bone and Mineral Research and the Korean College of Rheumatology have developed this guideline based on Guidance for the Development of Clinical Practice Guidelines ver. 1.0 established by the National Evidence-Based Healthcare Collaborating Agency. This guideline was developed by adapting previously published guidelines, and a systematic review and quality assessment were performed. Results: This guideline applies to adults aged $\geq 19$ years who are using or plan to use GCs. It does not include children and adolescents. An initial assessment of fracture risk should be performed within 6 months of initial GC use. Fracture risk should be estimated using the fracture-risk assessment tool (FRAX) after adjustments for GC dose, history of osteoporotic fractures, and bone mineral density (BMD) results. All patients administered with prednisolone or an equivalent medication at a dose $\geq 2.5 \mathrm{mg} /$ day for $\geq 3$ months are recommended to use adequate calcium and vitamin $\mathrm{D}$ during treatment. Patients showing a moderate-tohigh fracture risk should be treated with additional medication for osteoporosis. All patients continuing GC therapy should undergo annual BMD testing, vertebral X-ray, and fracture risk assessment using FRAX. When treatment failure is suspected, switching to another drug should be considered. Conclusions: This guideline is intended to guide clinicians in the prevention and treatment of GIOP.

Key Words: Bisphosphonate · Denosumab · Glucocorticoids · Osteporosis · Teriparatide

\section{INTRODUCTION}

Glucocorticoids (GCs) are very effective drugs for the treatment of inflammatory diseases and have been widely used in various diseases.[1-3] However, long-term use of GCs has detrimental effects on bone microstructure, leading to a decrease in bone mass and an increase in the risk of fracture.[3,4] It is estimated that frac- 
tures occur in $30 \%$ to $50 \%$ of patients receiving long-term GC therapy, but many patients have no symptoms of fracture because of the analgesic effects of GCs.[5-7] There are no definitive data on the number of patients receiving GCs for 3 months or longer in Korea, but it is estimated to be much higher than the $1 \%$ reported in other countries.[8,9] Therefore, GC-induced osteoporosis (GIOP) is recognized as the most common cause of secondary osteoporosis and, because there may be no specific symptoms, active management focused on prevention is needed.

The decrease of bone mass caused by GCs occurs in 2 stages. First, a rapid decrease in bone mass begins within the first 3 to 6 months of GC use, with a $6 \%$ to $12 \%$ loss of bone mass in the first year of GC use.[10] Second, longterm use of GCs can result in a 3\% reduction in bone mass every year.[11] GCs affect both cortical bone and trabecular bone, but fractures occur most commonly in the vertebral body, especially in areas rich in trabecular bone, such as the lumbar spine. $[3,4,12]$ The risk of GC-induced fracture is already increased before a significant reduction in bone mass occurs.[3] Therefore, measurements of bone mineral density (BMD) are not sufficient to evaluate the degree of GC-induced bone loss, so it is very important to identify patients with a high risk of fracture to prevent fractures caused by GIOP.[13-15] The absolute risk of an individual fracture is determined by age, gender and other risk factors for osteoporosis. Currently, fracture-risk assessment tool (FRAX) is a well-known method for assessing the risk of fracture. In addition to the risk factors included in the FRAX, low bone strength at the beginning of GC treatment and the rate of bone loss during treatment are suggested as risk factors for $\mathrm{GC}$-induced fractures, the latter being determined by the dose and duration of GC treatment.[16] In a study of individual absolute fracture probability, patients receiving prednisolone at a dose greater than $30 \mathrm{mg} /$ day (cumulative dose $>5 \mathrm{~g} /$ year) showed significantly increased risk of vertebral and femoral fractures.[17] However, if GC treatment is terminated, BMD gradually increases and fracture risk decreases. Therefore, patients could benefit from continuous risk assessment with an emphasis on the appropriate duration of GC use. $[9,18,19]$

As evidence of fracture risk in patients using GCs accumulates, drugs that effectively prevent fractures have been developed. However, many primary care physicians and specialists fail to recognize the severity of GIOP or deter- mine which patients are at greatest risk for GIOP. Therefore, many patients still do not receive treatment to prevent fractures. To address this problem, guidelines for GIOP prevention and treatment have recently been developed by several countries. Notably, the guideline of the American College of Rheumatology (ACR) were revised in 2017 based on the latest evidence and applied to clinical practice.[16] In Korea, it is necessary to provide standardized clinical practical guideline $(C P G)$ for the primary prevention and treatment of GIOP to all clinicians, to ensure that Korean patients who plan to use or use GCs receive the appropriate services for fracture prevention. The Korean Society for Bone and Mineral Research (KSBMR) and the Korean College of Rheumatology (KCR) have mutually developed guideline for the treatment of GIOP. Because of limited domestic data, this guideline was developed by adapting previously-published guidelines.

\section{METHODS}

This guideline was developed for adults over the age of 19 who plan to use or currently use GCs. Pediatric populations and people with a glomerular filtration rate of $<30$ $\mathrm{mL} / \mathrm{min}$ were excluded. A development committee and a working committee were organized to develop guideline for the treatment of GIOP. These committees were composed of multi-disciplinary and multi-institutional organizations and included endocrinologists, rheumatologists, an orthopedist, and a methodologist (Supplementary Appendix 1). A systematic literature review was conducted, and guidelines were selected and adapted from the existing literature. The completed guideline should be revised within 5 years, and earlier revisions may be required if a new drug is approved for GIOP or if the evidence changes significantly.

\section{Framework for GIOP guideline development}

Methods were based on guidance for the development of CPGs version 1.0 by the National Evidence-Based Healthcare Collaborating Agency (NECA) (Supplementary Appendix 2). The process of developing this guideline included 3 major stages [20]: planning, development, and finalization. Each stage was divided into individual steps, for a total of 12 steps. The planning stage consisted of selecting topics (Step 1), assembling the development commit- 
tee (Step 2), reviewing previously published guidelines (Step 3), establishing the development plan (Step 4), and selecting key questions (KQs) (Step 5). The development stage consisted of searching for, evaluating, and synthesizing evidence (Steps 6-8), making recommendations and determining the grades of recommendations (Step 9), and consensus building (Step 10). The finalization stage consisted of external reviews and publications (Steps 11 and 12).

\section{Selection of KQs}

To select the KQs to be addressed by the GIOP guideline, a working committee consisting of a total of nine members first reviewed six guidelines developed by the United States, France, Spain, Japan, Brazil, and the International Osteoporosis Foundation-European Calcified Tissue Society (IOF-ECTS). From these 6 guidelines, the committee selected 14 topics. After reviewing these topics, the development committee considered domestic circumstances and clinical significance to select the most relevant KQs. A final list of seven KQs was chosen, which included the patient population $(\mathrm{P})$, the intervention $(\mathrm{I})$, the comparator $(\mathrm{C})$, and the outcome of the intervention (0) (PICO; Table 1).

\section{Literature search}

Two members of the working committee performed systematic literature searches, using the databases PubMed,
OVID-EMBASE, KoreaMed, KMbase, National Guideline Clearinghouse, Guidelines International Network, and Korean Medical Guideline Information Center (KoMGI). The researchers identified a total of 309 potentially relevant articles published since 2010, excluding duplicates. By reviewing titles and abstracts, the researchers narrowed this list to the 27 most relevant articles. From these 27 articles, 7 of previously-published guidelines were identified: (1) guidelines including PICO that are consistent with KQs; (2) evidence-based guidelines, which are defined by a clear link between the recommendation and the supporting evidence, including systematic literature searches; (3) guidelines for peer review; and (4) guidelines published in Korean or English (Fig. 1, Supplementary Appendix 3 and 4).

\section{Final selection process for guidelines}

Seven guidelines were chosen based on the systematic literature review, selection criteria, and exclusion criteria (Table 2).[21-27] A quality assessment was performed on these seven guidelines using the Appraisal of Guidelines for Research and Evaluation II (AGREE II). In this comprehensive assessment, the scope and objectives of the guidelines, strictness of development, participation of stakeholders, clarity of expression, applicability, and editorial independence were assessed.[28] The quality assessment of guidelines using AGREE II was conducted by 3

Table 1. Key questions

\begin{tabular}{|c|c|}
\hline No. & Questions \\
\hline K01. & Is non-pharmacological treatment beneficial for the prevention and treatment of GIOP in adults taking GCs? \\
\hline K02. & Which pharmacological treatments are effective for prevention and treatment of GIOP in adults $<40$ years of age? \\
\hline K02-1. & Is calcium and vitamin D supplementation effective in the prevention and treatment of GIOP in adults $<40$ years of age? \\
\hline K02-2. & Is bisphosphonate effective in the prevention and treatment of GIOP in adults $<40$ years of old? \\
\hline K02-3. & Is teriparatide effective in the prevention and treatment of GIOP in adults $<40$ years of old? \\
\hline K02-4. & Is denosumab effective in the prevention and treatment of GIOP in adults $<40$ years of old? \\
\hline K03. & Which pharmacological treatments are effective for prevention and treatment of GIOP in adults $\geq 40$ years of age? \\
\hline K03-1. & Is calcium and vitamin D supplementation effective in the prevention and treatment of GIOP in adults $\geq 40$ years of age? \\
\hline K03-2. & Is bisphosphonate effective in the prevention and treatment of GIOP in adults $\geq 40$ years of old? \\
\hline K03-3. & Is teriparatide effective in the prevention and treatment of GIOP in adults $\geq 40$ years of old? \\
\hline K03-4. & Is denosumab effective in the prevention and treatment of GIOP in adults $\geq 40$ years of old? \\
\hline K03-5. & Is selective estrogen receptor modulator effective in the prevention and treatment of GIOP in postmenopausal women? \\
\hline K04. & Is it safe to use osteoporosis medication in women planning to have a pregnancy? \\
\hline K05. & How should response to treatment be monitored in patients with GIOP using physical measurements, imaging, and biochemical methods? \\
\hline K06. & $\begin{array}{l}\text { Should discontinuation of osteoporosis medication be considered if the fracture risk is reassessed and determined to be low during } \\
\text { GIOP treatment? }\end{array}$ \\
\hline K07. & How should initial treatment failure be defined for GIOP? \\
\hline
\end{tabular}

KQ, key question; GIOP, glucocorticoid-induced osteoporosis; GCs, glucocorticoids. 


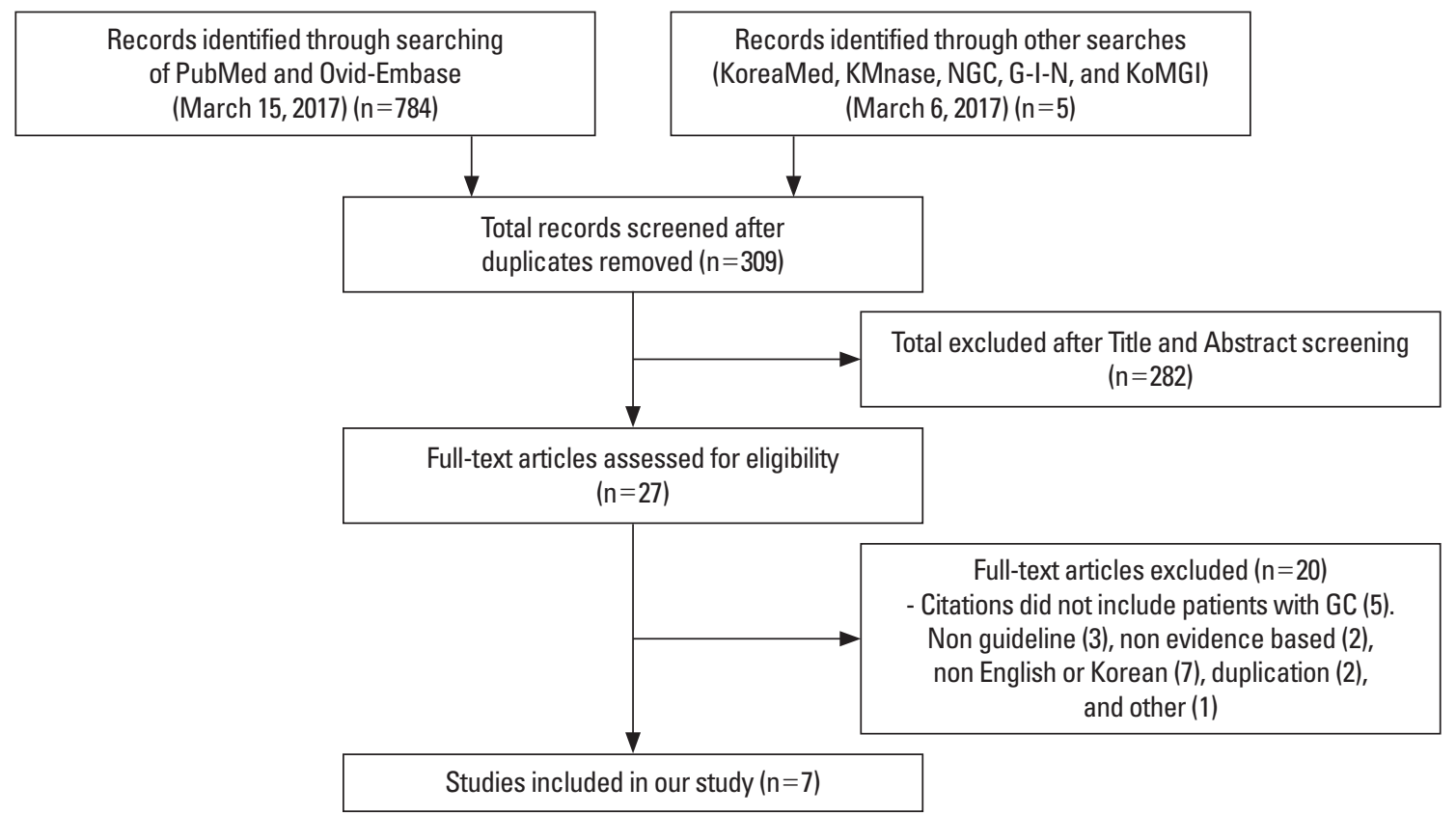

Fig. 1. Flowchart of the systematic search of literature and selection process for the development of glucocorticoid-induced osteoporosis by adaptation.

Table 2. The guidelines selected for 1st Appraisal of Guidelines for Research and Evaluation

\begin{tabular}{|c|c|c|c|}
\hline References & Year & Country & Institute \\
\hline Grossman et al.[21] & 2010 & USA & American College of Rheumatology \\
\hline Lekamwasam et al.[22] & 2012 & International & Joint IOF-ECTS GIOP Guidelines Working Group \\
\hline Pereira et al.[25] & 2012 & Brazil & $\begin{array}{l}\text { Committee for Osteoporosis and Bone Metabolic Disorders of the Brazilian Society of Rheumatology, } \\
\text { Brazilian Medical Association, and Brazilian Association of Physical Medicine and Rehabilitation }\end{array}$ \\
\hline Briot et al.[24] & 2014 & France & $\begin{array}{l}\text { Bone Section of the French Society for Rheumatology and Osteoporosis Research and Information } \\
\text { Group }\end{array}$ \\
\hline Suzuki et al.[26] & 2014 & Japan & Japanese Society for Bone and Mineral Research \\
\hline Papaioannou et al.[23] & 2010 & Canada & Scientific Advisory Council of Osteoporosis Canada \\
\hline Rossini et al.[27] & 2016 & Italy & The Italian Society for Osteoporosis, Mineral Metabolism and Bone Diseases \\
\hline
\end{tabular}

IOF-ECTS, International Osteoporosis Foundation-European Calcified Tissue Society; GIOP, glucocorticoid-induced osteoporosis.

members of the working committee as per recommendations, and the items with given divergent scores by the 3 researchers were reviewed and agreed upon. The strictness of development was specifically considered in the process of selecting guidelines. Four guidelines published in the United States (2010), IOF-ECTS (2012), Canada (2010) and France (2014) were selected.[21-24]

During the selection of guidelines, the National Osteoporosis Guideline Group (NOGG) and the ACR published new guidelines for GIOP treatment in 2017.[16,29] Therefore, the 2010 ACR guideline was replaced by the 2017 ACR guideline (Table 3 ), and the quality assessment was reevaluated for the 5 guidelines. The 2017 ACR guidelines,
Table 3. The additional guidelines for 2nd Appraisal of Guidelines for Research and Evaluation

\begin{tabular}{lccc}
\hline References & Year & Country & Institute \\
\hline Buckley et al.[16] & 2017 & USA & American College of Rheumatology \\
Compston et al.[29] & 2017 & UK & $\begin{array}{c}\text { National Osteoporosis Guideline } \\
\text { Group }\end{array}$ \\
\hline
\end{tabular}

which ranked highly in items of "comprehensive evaluation" and "strictness of development", were chosen and adapted (Supplementary Appendix 5). The characteristics of final 5 guidelines were summarized in Supplementary Appendix 6. 
Table 4. The level of evidence

\begin{tabular}{|c|c|c|}
\hline The level & Expression & Type of evidence \\
\hline I & High & $\begin{array}{l}\text { Further research is very unlikely to change our confidence in the estimate of effect (systematic overview of meta-analysis } \\
\text { of randomized controlled trials). }\end{array}$ \\
\hline ॥ & Moderate & $\begin{array}{l}\text { Further research is likely to have an important impact on our confidence in the estimate of effect and may change the } \\
\text { estimate (not applicable by I, prospective observation study, case-control study). }\end{array}$ \\
\hline III & Low & $\begin{array}{l}\text { Further research is very likely to have an important impact on our confidence in the estimate of effect and is likely to } \\
\text { change the estimate (retrospective observation study, case-control study). }\end{array}$ \\
\hline IV & Very low & We are very uncertain about the estimate. \\
\hline EC & Expert consensus & $\begin{array}{l}\text { Evidence from expert committees without explicit critical scientific analysis or that based on physiology, basic research } \\
\text { or first principles. }\end{array}$ \\
\hline
\end{tabular}

Table 5. The grade of recommendations

\begin{tabular}{|c|c|c|}
\hline Grade & Expression & Type of recommendations \\
\hline A & Recommended & It is recommended that the intervention be conducted with sufficient evidence of the desired effect. \\
\hline B & Conditionally recommended & $\begin{array}{l}\text { The evidence for the desired effect of the intervention is between moderate and high grounds. It is recommended } \\
\text { that intervention (inspection) be provided selectively, or to be conducted to a specific individual at the discretion } \\
\text { of the expert. }\end{array}$ \\
\hline C & Not recommended & $\begin{array}{l}\text { There is sufficient evidence on the undesirable effects of the arbitration, and it is not recommended } \\
\text { (not recommended). }\end{array}$ \\
\hline I & No recommendation & $\begin{array}{l}\text { There is insufficient evidence that the intervention is effective or not, and further study of the effect is needed. } \\
\text { The degree of confidence in the effectiveness of the intervention is so low that it is judged that the recom- } \\
\text { mendation rating itself is not meaningful. }\end{array}$ \\
\hline
\end{tabular}

\section{Writing process for guidelines}

The working committee reviewed the recommendations and evidence for the final 5 guidelines, and then summarized the primary recommendations for KQs (Supplementary Appendix 7). The acceptability and applicability of the recommendations of final 5 guidelines to the KQ was assessed (Supplementary Appendix 8). After collecting the opinions of all committee members, the final recommendations were completed. If there was a lack of evidence or a need for clinical interpretation, the consensus process proceeded among the members of the working committee. The strength of evidence was divided into 5 levels (Table 4), and recommendation grade was assessed considering the level of evidence and clinical effects, patient satisfaction, quality of life, harmful reactions, and unnecessary use of resources (Table 5). The final recommendation grade was decided on the principle of agreement of more than $80 \%$, along with the consent of the working committee.

\section{Selection of eligible patients and fracture risk assessment}

The development committee and working committee decided to apply the 2017 ACR guideline for the fracture risk classification and assessment, because relatively little evidence was available beyond these guidelines. Tables and figures were used with permission from the original author.

\section{RESULTS}

\section{Fracture risk classification}

It is important to classify patients according to fracture risk before deciding whether to use fracture-prevention treatments. To predict fracture risk, we decided to use FRAX, which is widely used in many guidelines for GIOP, including the 2017 ACR guidelines. In addition to FRAX, we also considered using history of previous fracture, BMD, and $G C$ dose as predictors. Patients aged $\geq 50$ years have been the focus of many studies of osteoporosis. However, FRAX applies only to patients $\geq 40$ years old, so we divided our recommendations by adults $\geq 40$ years for whom FRAX is applicable, and those under 40 years old who are not included in FRAX. Fracture risk was classified as high, moderate, and low (Table 6). For example, the high risk category included patients $\geq 40$ years of age with previous osteoporotic fracture, BMD T-score $\leq-2.5$ in men who are $\geq 50$ years of age or postmenopausal women, FRAX-calculated 10 -year major osteoporotic fracture risk $\geq 20 \%$, or 
FRAX-calculated 10 -year hip fracture risk $\geq 3 \%$. The risk of fracture is correlated with prednisolone dose. For patients taking prednisolone at a dose $>7.5 \mathrm{mg} /$ day, FRAX calculates an increase in fracture risk of $15 \%$ for major osteopo-

Table 6. Fracture risk categories in glucocorticoid-treated patients

\begin{tabular}{|c|c|c|}
\hline Fracture risk & Adults $\geq 40$ years of age & Adults $<40$ years of age \\
\hline High fracture risk & $\begin{array}{l}\text { Prior osteoporotic fracture(s) } \\
\text { Hip or spine bone mineral density } \\
\text { T-score } \leq-2.5 \text { in men age } \geq 50 \text { years and postmenopausal women } \\
\text { FRAX }^{\text {al) }}(G C \text {-adjusted })^{\text {b) }} 10 \text {-year risk of major osteoporotic fracture }{ }^{c} \geq 20 \% \\
\text { FRAX }^{\text {al }}(G C \text {-adjusted })^{\text {b) }} 10 \text {-year risk of hip fracture } \geq 3 \%\end{array}$ & Prior osteoporotic fracture(s) \\
\hline Moderate fracture risk & $\begin{array}{l}\text { FRAX }^{\text {al) }}(G C \text {-adjusted })^{\text {b) }} 10 \text {-year risk of major osteoporotic fracture }{ }^{\text {c) }} 10-19 \% \\
\text { FRAX }^{\text {al }}(G C \text {-adjusted })^{\text {b) }} 10 \text {-year risk of hip fracture }>1 \% \text { and }<3 \%\end{array}$ & $\begin{array}{l}\text { Hip or spine bone mineral density Z-score } \\
<-3 \text { or rapid bone loss ( } \geq 10 \% \text { at the hip } \\
\text { or spine over } 1 \text { year) and continuing GC } \\
\text { treatment at } \geq 7.5 \mathrm{mg} / \text { day for } \geq 6 \text { months }\end{array}$ \\
\hline Low fracture risk & $\begin{array}{l}\text { FRAX }^{\text {al }}(G C \text {-adjusted })^{\text {b) }} 10 \text {-year risk of major osteoporotic fracture }{ }^{\mathrm{c})}<10 \% \\
\text { FRAX }^{\text {al }}(G C \text {-adjusted })^{\text {b) }} 10 \text {-year risk of hip fracture } \leq 1 \%\end{array}$ & $\begin{array}{l}\text { None of above risk factors other than } \mathrm{GC} \\
\text { treatment }\end{array}$ \\
\hline
\end{tabular}

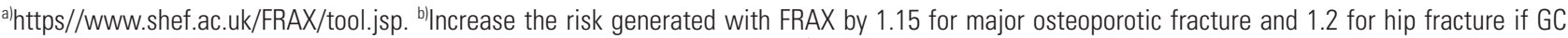
treatment is $.7 .5 \mathrm{mg} /$ day (i.e., if hip fracture risk is 2.0\%, increase to $2.4 \%$ ). ${ }^{c}$ Major osteoporotic fracture includes fractures of the spine (clinical), hip, wrist, or humerus.

FRAX, fracture-risk assessment tool; GC, glucocorticoid.

[Reprinted from "2017 American College of Rheumatology Guideline for the Prevention and Treatment of Glucocorticoid-Induced Osteoporosis.", by Buckley L, et al., 2017, Arthritis Care Res (Hoboken), 69, pp.1095-1110. Copyright 2017 by the Wiley. Reprinted with permission].

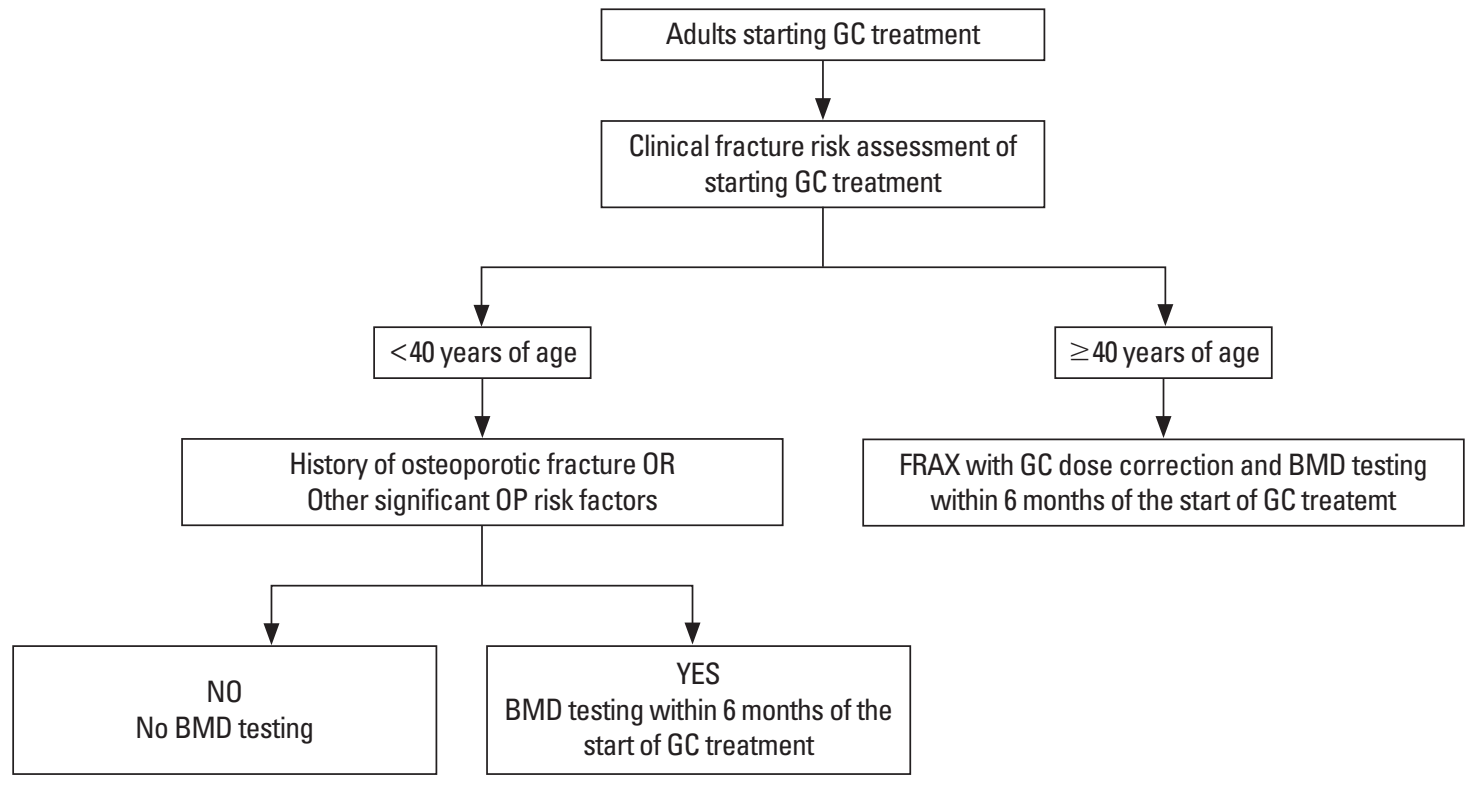

Fig. 2. Initial fracture risk assessment. A clinical fracture risk assessment includes obtaining a history with the details of GC use (dose, duration, pattern of use), an evaluation for falls, fractures, frailty, and other OP risk factors (malnutrition, significant weight loss or low body weight, hypogonadism, secondary hyperparathyroidism, thyroid disease, family history of hip fracture, history of alcohol use [at $\geq 3$ units/day] or smoking) and other clinical comorbidities, and a physical examination including measurement of weight and height (without shoes), testing of muscle strength, and assessment for other clinical findings of undiagnosed fracture (i.e., spinal tenderness, deformity, and reduced space between lower ribs and upper pelvis) as appropriate given the patient's age. The risk of major osteoporotic fracture calculated with the fracture-risk assessment tool (FRAX) should be increased by 1.15, and the risk of hip fracture by 1.20 , if the prednisone dose is $7.5 \mathrm{mg} /$ day (i.e., if the calculated hip fracture risk is $2.0 \%$, increase to $2.4 \%$ ). It is recognized that in some cases, BMD testing may not be available. GC, glucocorticoid; OP, osteoporosis; BMD, bone mineral density. [Reprinted from "2017 American College of Rheumatology Guideline for the Prevention and Treatment of Glucocorticoid-Induced Osteoporosis.", by Buckley L, et al., 2017, Arthritis Care Res (Hoboken), 69, pp.1095-1110. Copyright 2017 by the Wiley. Reprinted with permission]. 
rotic fracture and $20 \%$ for hip fracture risk.[30]

\section{Fracture risk assessment}

1) Initial fracture risk assessment

The initial fracture risk assessment should be performed as early as possible in patients with long-term GC treatment. It is appropriate to assess the fracture risk within 6 months of the initiation of long-term GC treatment, and to consider the calculated risks when selecting the specific GC treatment (Fig. 2). The most important factors in the initial assessment are the dose, duration, and method of administration of GCs, and history of previous fracture, fall, and frailty. The current nutritional status, weight loss, and the possibility of secondary osteoporosis, including thyroid disease, need to be evaluated carefully. In particular, it is necessary to investigate the variables included in FRAX (history of previous fracture, comorbidities, smoking history, alcohol consumption, family history of fracture) in patients $\geq 40$ years of age. Adjusting FRAX for GC dose and $B M D$ testing are also necessary. If a patient $<40$ years of age has risk factors for fracture (previous osteoporotic fracture, malnutrition, thyroid disease, weight loss, secondary hyperparathyroidism, hypogonadism, family history of femoral fracture, smoking, alcohol consumption, etc.), it is important to conduct a BMD early in treatment to assess fracture risk further.

\section{2) Reassessment of fracture risk}

If GCs are used continuously, it is necessary to reassess the risk of fracture every 12 months (Fig. 3). For adults $\geq 40$

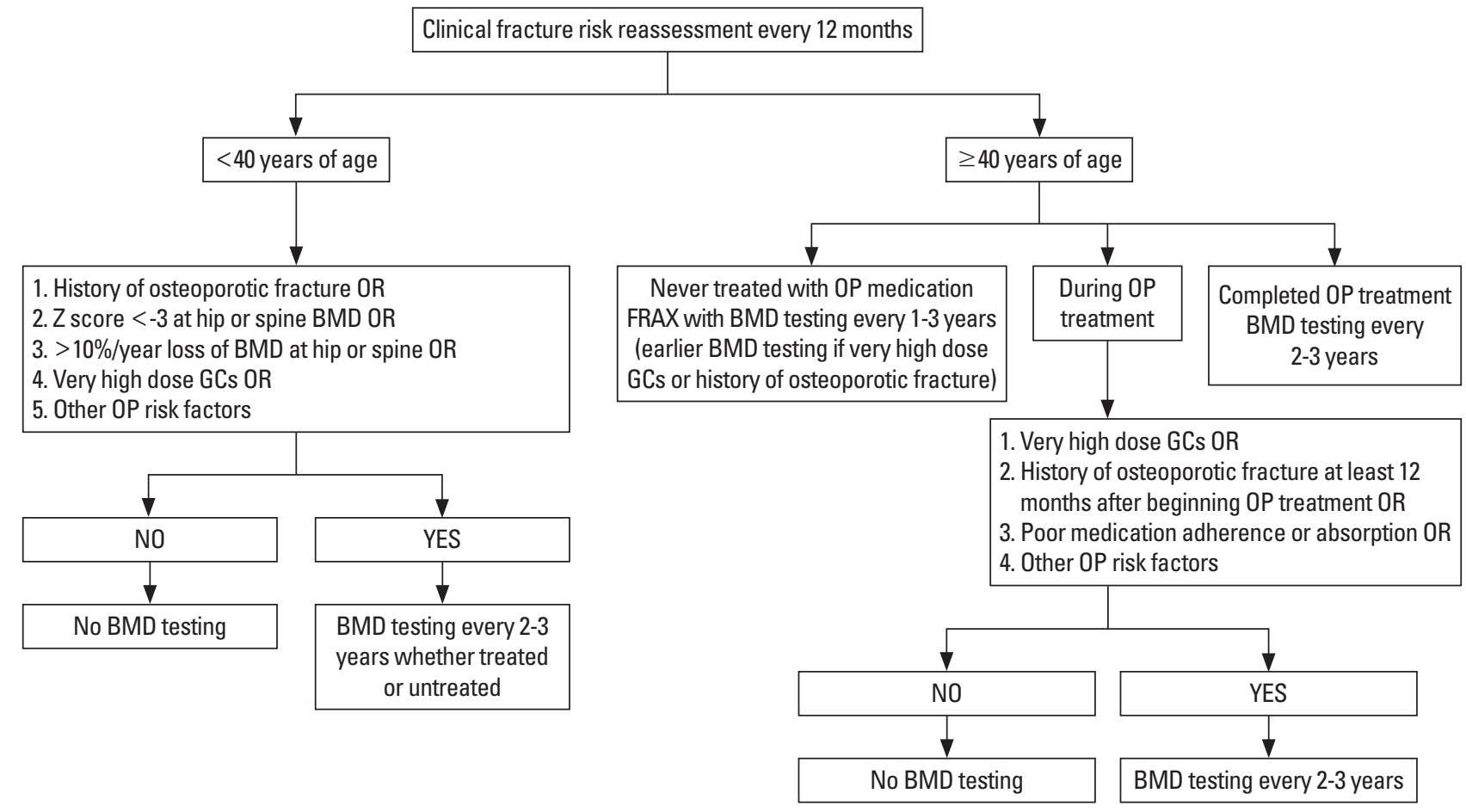

Fig. 3. Reassessment of fracture risk. A clinical fracture risk assessment includes obtaining a history with the details of GC use (dose, duration, pattern of use), an evaluation for falls, fractures, frailty, and other OP risk factors (malnutrition, significant weight loss or low body weight, hypogonadism, secondary hyperparathyroidism, thyroid disease, family history of hip fracture, history of alcohol use [at $\geq 3$ units/day] or smoking) and other clinical comorbidities, and a physical examination including measurement of weight and height (without shoes), testing of muscle strength, and assessment for other clinical findings of undiagnosed fracture (i.e., spinal tenderness, deformity, and reduced space between lower ribs and upper pelvis) as appropriate given the patient's age. Very high-dose GC treatment was defined as treatment with prednisone $\geq 30 \mathrm{mg} /$ day and a cumulative dose of $5 \mathrm{~g}$ in the past year. Reliability of fracture-risk assessment tool (FRAX) after OP treatment is debated, but FRAX calculation can be repeated in adults age $\geq 40$ years who have not received treatment. It is recognized that in some cases, BMD testing may not be available. GC, glucocorticoid; OP, osteoporosis; BMD, bone mineral density. [Reprinted from "2017 American College of Rheumatology Guideline for the Prevention and Treatment of Glucocorticoid-Induced Osteoporosis.", by Buckley L, et al., 2017, Arthritis Care Res (Hoboken), 69, pp.1095-1110. Copyright 2017 by the Wiley. Reprinted with permission]. 
years of age who continue GC treatment and are not treated with osteoporosis medications beyond calcium and vitamin D, FRAX and BMD should be performed every 1 to 3 years. FRAX and BMD are recommended every year if the initial GC dose is prednisolone $\geq 30 \mathrm{mg} /$ day, if the cumulative dose is greater than $5 \mathrm{~g}$ in the previous year, or if osteoporotic fractures have occurred.

For adults $\geq 40$ years of age who are at high risk of fracture (initial GC dose of prednisolone $\geq 30 \mathrm{mg} /$ day, cumulative dose $>5 \mathrm{~g} /$ year, osteoporotic fracture occurring $\geq 12$ months after beginning osteoporosis medications, poor medication adherence or absorption, or other significant osteoporosis risk factors) who are taking osteoporosis medications with GC treatment, BMD testing should be completed every 2 to 3 years and is recommended as early as possible. BMD testing should be performed at intervals as soon as possible, even after discontinuation of osteoporosis medication.

For adults $<40$ years of age who have moderate or high risk and are receiving continuous GC treatment, BMD testing should be conducted every 2 to 3 years.

\section{Treatment and follow-up of GIOP}

1) KQ1: Is non-pharmacological treatment beneficial for the prevention and treatment of GIOP in adults taking GCs?

Non-pharmacological treatments such as exercise, good nutrition, smoking cessation, and avoiding alcohol abuse are recommended for all adults taking GCs. Because there is insufficient evidence for the effects of these treatments in GIOP, it is recommended that treatment be based on data from these treatments in postmenopausal osteoporosis patients [III/B].

Because there are limited data on effects of non-pharmacological treatments in the prevention and treatment of GIOP, it is recommended that treatment be based on the established non-pharmacological treatment of postmenopausal osteoporosis patients. Although the effects of these lifestyle modifications on fracture risk have not been established for patients with GIOP, non-pharmacological treatments such as weight-bearing exercise, good nutrition, smoking cessation, and avoiding alcohol abuse is recommended for all adults taking GCs [III/B].

\section{2) KQ2: Which pharmacological treatments are} effective for prevention and treatment of GIOP in adults $<40$ years of age?

There are few randomized controlled trials comparing the effects of drugs on prevention of bone mass loss and fracture for this age group. This is because adults $<40$ years of age have relatively high BMD and fewer fractures than postmenopausal women. However, it is reported that long-term use of GCs in premenopausal women $<40$ years of age may cause changes in bone structure and weaken bone strength.[31,32] Initial pharmacologic treatment for adults $<40$ years of age is summarized in Figure 4.

\section{(1) KQ2-1: Is calcium and vitamin D supplementation effective in the prevention and treatment of GIOP in adults $<40$ years of age?}

(1) Calcium and vitamin D are recommended for all adults taking prednisone $\geq 2.5 \mathrm{mg} /$ day for $\geq 3$ months [ll/B].

(2) Sufficient calcium $(1,000-1,200 \mathrm{mg})$ and vitamin D (800 IU) intake are recommended, and adequate vitamin $D$ concentrations ( $\geq 20 \mathrm{ng} / \mathrm{mL}$ ) should be maintained [Expert consensus/B].

(3) The use of supplements should be considered when dietary intake of calcium and vitamin $D$ is insufficient [Expert consensus/B].

(4) The minimum adequate dosage should be determined, because high doses of calcium and vitamin D supplementation may increase the risk of gastrointestinal side effects and renal stones [Expert consensus/B].

GCs reduce intestinal absorption and renal reabsorption of calcium, and increase calcium excretion into the urine. [33] Therefore, calcium and vitamin D are recommended for adults $<40$ years of age who are taking prednisolone $\geq 2.5 \mathrm{mg}$ for $\geq 3$ months [II/B]. However, calcium alone is not effective in the prevention and treatment of GIOP,[34, $35]$ it is more effective to take calcium and vitamin $D$ together. Patients receiving vitamin D3 (cholecalciferol) $[36,37]$ or activated vitamin D (calcitriol, alphacalcidol) $[38,39]$ in combination with calcium showed an inhibitory effect on bone loss compared to calcium alone or no treatment. Adequate intake of calcium $(1,000-1,200 \mathrm{mg})$ and vitamin $D$ (800 IU) are recommended to maintain vitamin D concen- 


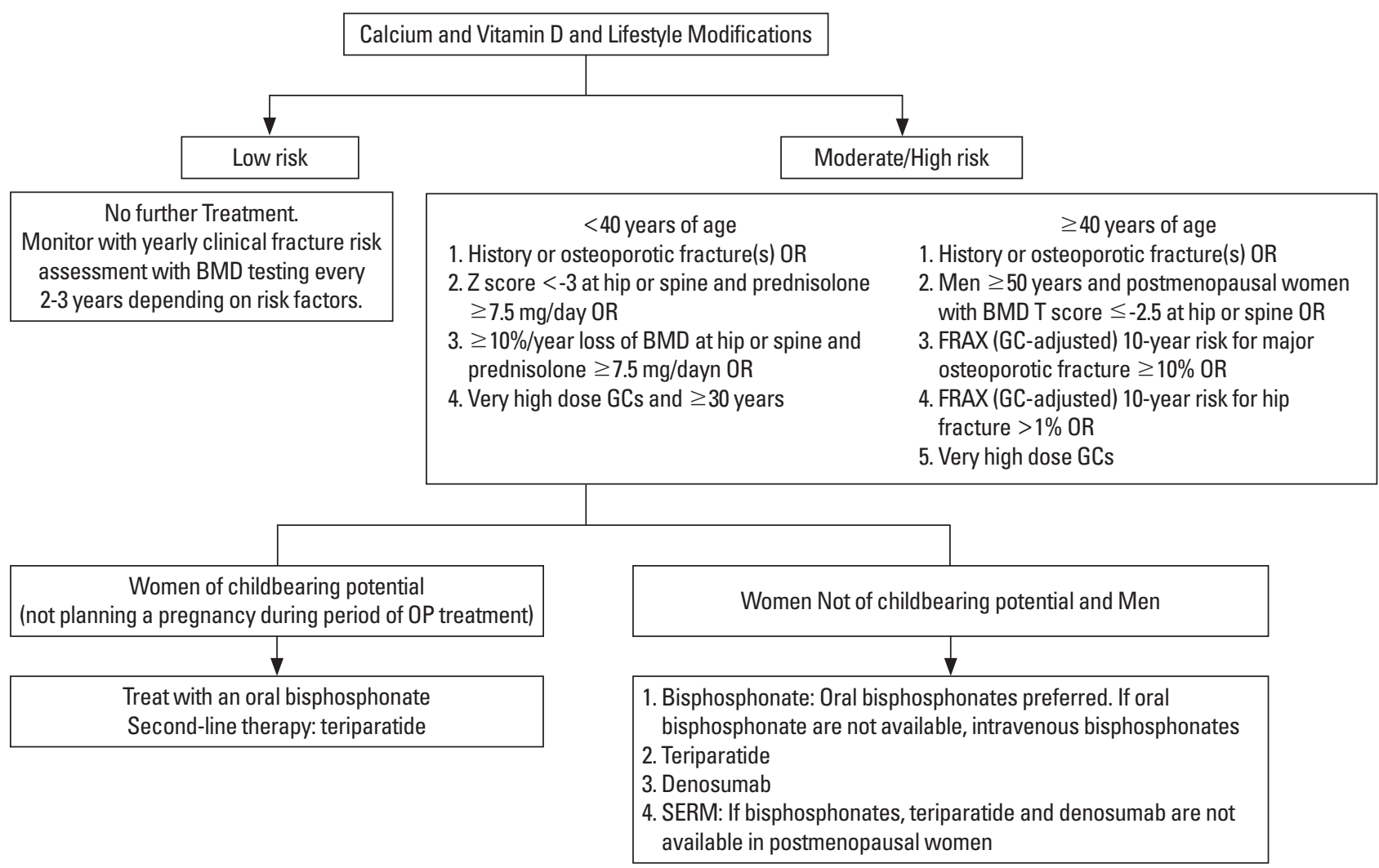

Fig. 4. Initial pharmacologic treatment for adults. Recommended doses of calcium and vitamin D are 1,000 to 1,200 mg/day and 600 to $800 \mathrm{IU} /$ day (serum level $\geq 20 \mathrm{ng} / \mathrm{mL}$ ), respectively. Lifestyle modifications include a balanced diet, maintaining weight in the recommended range, smoking cessation, regular weight-bearing and resistance training exercise, and limiting alcohol intake to 1 to 2 alcoholic beverages/day. Very high-dose GC treatment was defined as treatment with prednisone $\geq 30 \mathrm{mg} /$ day and a cumulative dose of $>5 \mathrm{~g}$ in the past year. The risk of major OP fracture calculated with the fracture-risk assessment tool (FRAX) should be increased by 1.15, and the risk of hip fracture by 1.2, if the prednisone dose is $>7.5 \mathrm{mg} /$ day (i.e., if the calculated hip fracture risk is $2.0 \%$, increase to $2.4 \%$ ). It is recognized that in some cases, BMD testing may not be available. BMD, bone mineral density; OP, osteoporosis; GC, glucocorticoid; SERM, selective estrogen receptor modulating agent. [Reprinted from "2017 American College of Rheumatology Guideline for the Prevention and Treatment of Glucocorticoid-Induced Osteoporosis.", by Buckley L, et al., 2017, Arthritis Care Res (Hoboken), 69, pp.1095-1110. Copyright 2017 by the Wiley. Reprinted with permission].

tration ( $\geq 20 \mathrm{ng} / \mathrm{mL}$ ) [Expert consensus/B]. The use of supplements may be considered if the intake of calcium and vitamin $D$ through meals is insufficient [Expert consensus/B].

\section{(2) KQ2-2: Is bisphosphonate effective in the prevention and treatment of GIOP in adults $<40$ years of age?}

(1) Oral bisphosphonates are recommended for adults $<40$ years of age with moderate to high risk of fracture $[\mathrm{II} / \mathrm{A}]$.

(2) If oral bisphosphonates are not appropriate intravenous bisphosphonate is recommended [II/A].
Bisphosphonates are recommended for women without childbearing potential and men $<40$ years of age at moderate to high fracture risk [II/A]. Alendronate was effective in prevention of bone loss and fractures in premenopausal women with high-dose GC therapy.[40] Subgroup analysis of adults $<40$ years of age has been done in several previously published studies on GIOP treatment. These studies have shown that bisphosphonates such as alendronate,[4045] risedronate,[46-48] zoledronic acid [49] increased BMD and decreased fracture risk compared to placebo or calcium/vitamin D. Oral bisphosphonates, which have a relatively short half-life, are preferred. If oral bisphosphonates are not appropriate, intravenous bisphosphonate is recommended. 


\section{(3) KQ2-3: Is teriparatide effective in the prevention and treatment of GIOP in adults $<40$ years old?}

Teriparatide is recommended for adults $<40$ years old with moderate to high risk of fracture [II/A].

Teriparatide is recommended for women without childbearing potential and men $<40$ years of age at moderate to high fracture risk [II/A]. Among patients taking prednisolone $\geq 5 \mathrm{mg} /$ day for $\geq 3$ months, teriparatide treatment led to significantly higher spine BMD than alendronate treatment in both postmenopausal and premenopausal women.[50]

\section{(4) KQ2-4: Is denosumab effective in the prevention and} treatment of GIOP in adults $<40$ years of age?

Denosumab is recommended for adults $<40$ years of old with moderate-to-high risk of fracture [II/A].

Denosumab is recommended for women without childbearing potential and men $<40$ years of age at moderateto-high fracture risk [II/A]. Recently, in a randomized, double-blind, comparative study of denosumab versus risedronate in patients $\geq 19$ years of age taking prednisolone $\geq 7.5 \mathrm{mg} /$ day for $\geq 3$ months, denosumab significantly increased spine and hip BMD compared to risedronate.[51]

3) KQ3: Which pharmacological treatments are effective for the prevention and treatment of GIOP in adults $\geq 40$ years of age?

Initial pharmacologic treatment for adults $\geq 40$ years of age is summarized in Figure 4.

(1) KQ3-1: Is calcium and vitamin D supplementation effective in the prevention and treatment of GIOP in adults $\geq 40$ years of age?

(1) Calcium and vitamin D are recommended for all adults taking prednisolone $\geq 2.5 \mathrm{mg} /$ day for $\geq 3$ months [II/B].

(2) Sufficient calcium $(1,000-1,200 \mathrm{mg})$ and vitamin $D$ (800 IU) intakes are recommended, and adequate vitamin D concentrations ( $\geq 20 \mathrm{ng} / \mathrm{mL}$ ) should be maintained [Expert consensus/B].

(3) The use of supplements should be considered when the intake of calcium and vitamin $D$ through meals is insufficient [Expert consensus/B].

(4) The adequate dosage should be considered, because high doses of calcium and vitamin D supplementation may increase the risk of gastrointestinal side effects and renal stones [Expert consensus/B].

Recommendations for calcium and vitamin D supplementation in adults $\geq 40$ years of age are the same as for adults $<40$ years of age. Calcium and vitamin $D$ are recommended for adults $\geq 40$ years of age who are taking prednisolone $\geq 2.5 \mathrm{mg}$ for $\geq 3$ months [II/B]. Sufficient calcium $(1,000-1,200 \mathrm{mg})$ and vitamin $\mathrm{D}$ (800 IU) intake are recommended, and adequate vitamin D concentrations ( $\geq 20$ $\mathrm{ng} / \mathrm{mL}$ ) should be maintained [Expert consensus/B]. The use of supplements should be considered when the intake of calcium and vitamin D through meals is insufficient [Expert consensus/B]. The adequate dosage should be considered, because high doses of calcium and vitamin $D$ supplementation may increase the risk of gastrointestinal side effects and renal stones [Expert consensus/B].[52] There are concerns about increased risk of cardiovascular disease due to calcium intake, but a recent meta-analysis reported that calcium intake did not increase cardiovascular outcomes and mortality, regardless of the combination of vitamin D agents.[53]

\section{(2) KQ3-2: Is bisphosphonate effective in the prevention and treatment of GIOP in adults $\geq 40$ years of age?}

(1) Oral bisphosphonates are recommended for adults $\geq 40$ years of age with moderate-to-high risk of fracture $[\mathrm{l} / \mathrm{A}]$.

(2) If oral bisphosphonates are not appropriate, intravenous bisphosphonate is recommended [I/A].

(3) There is no evidence of increased side effects such as atypical femoral fractures or osteonecrosis of the jaw caused by bisphosphonates in patients with GIOP. However, when planning long-term bisphosphonates use in patients with GIOP, the risk-benefit ratio should be considered [Expert consensus/B]. 
Oral bisphosphonates are recommended for adults $\geq 40$ years of age with moderate-to-high risk of fracture. If oral bisphosphonates are not appropriate, intravenous bisphosphonate is recommended [I/A]. Alendronate and risedronate can be used as oral bisphosphonates, and the effects of alendronate $[41-45,54,55]$ and risedronate $[46-48,56-58]$ on the prevention and treatment of GIOP have been demonstrated through several studies. Ibandronate, an oral bisphosphonate, has been shown to increase spine and hip BMD and decrease bone turnover markers compared to placebo in postmenopausal women taking GCs for rheumatic diseases.[59] However, evidence for the use of ibandronate for GIOP prevention is still insufficient. Zoledronic acid was superior to risedronate as an intravenous bisphosphonate for the prevention and treatment of GIOP.[49,60] Bisphosphonates are associated with osteonecrosis of the jaw [6163] or atypical femoral fracture,[64-69] but there is no evidence of increased side effects caused by bisphosphonates in patients with GIOP. However, when planning long-term bisphosphonate use in patients with GIOP, the risk-benefit ratio should be considered [Expert consensus/B].

\section{(3) KQ3-3: Is teriparatide effective in the prevention and treatment of GIOP in adults $\geq 40$ years of age?}

Teriparatide is recommended for adults $\geq 40$ years of age with moderate-to-high risk of fracture [I/A].

Teriparatide is recommended for adults $\geq 40$ years of age with moderate-to-high risk of fracture [I/A]. When comparing the use of teriparatide with that of estrogen for 12 months in postmenopausal women with GIOP, spine and hip BMD were significantly increased in the teriparatide group, and there was no difference in forearm BMD between the 2 groups.[70] In addition, the use of teriparatide for 18 months or 36 months led to a significant increase in the spine and hip BMD, and reduction of vertebral fracture risk, compared with the use of alendronate. However, there was no difference in the reduction effect of nonvertebral fracture risk between the 2 groups. $[50,71,72]$

\section{(4) KQ3-4: Is denosumab effective in the prevention and} treatment of GIOP in adults $\geq 40$ years of age?

Denosumab is recommended for adults $\geq 40$ years of age with moderate-to-high risk of fracture [I/A].
Denosumab is recommended for adults $\geq 40$ years of age with moderate-to-high risk of fracture [I/A]. For patients with rheumatoid arthritis taking methotrexate and prednisolone $\geq 2.5 \mathrm{mg} /$ day for $\geq 3$ months, the effects of denosumab on BMD and bone turnover were compared with placebo. Denosumab treatment increased spine and hip BMD and reduced bone turnover markers for 12 months.[73] Recently, in a randomized, double-blind, comparative study of denosumab and risedronate in patients $\geq 19$ years of age taking prednisolone $\geq 7.5 \mathrm{mg} /$ day for $\geq 3$ months, denosumab significantly increased spine and femoral BMD compared to risedronate.[51]

\section{(5) KQ3-5: Is selective estrogen receptor modulator (SERM) effective in the prevention and treatment of GIOP in postmenopausal women?}

In the treatment of GIOP, SERM agents have not been sufficiently proven to be effective in the prevention of fractures. However, if bisphosphonates, teriparatide, and denosumab are not available to postmenopausal women with moderate-to-high risk of fracture, SERM should be considered [II/B].

In the treatment of GIOP, SERM has not been sufficiently proven to be effective in the prevention of fractures. However, if bisphosphonates, teriparatide, and denosumab are not available in postmenopausal women with moderateto-high risk of fracture, SERM should be considered [II/B]. For postmenopausal women taking prednisolone $\leq 10$ $\mathrm{mg} /$ day for $\geq 6$ months, 12 months of raloxifene treatment significantly increased lumbar spine and hip BMD and decreased bone turnover markers.[74]

4) KQ4: Is it safe to use osteoporosis medications in women planning to have a pregnancy?

(1) Oral bisphosphonates are preferred for women with moderate-to-high risk of fracture who are planning to have a pregnancy [Expert consensus/C].

(2) Teriparatide is considered in women with moderateto-high risk of fracture who are planning to have a pregnancy [Expert consensus/C].

(3) Because of lack of evidence of fetal safety, intravenous bisphosphonate and denosumab are not rec- 
ommended [Expert consensus/C].

(4) Osteoporosis medications except calcium and vitamin $\mathrm{D}$ are not recommended for use during pregnancy [Expert consensus/C].

Women who plan to become pregnant should be cautious in the use of osteoporosis medication [Expert consensus/C]. Oral bisphosphonates are preferred, and teriparatide is also considered for women with moderate-tohigh risk of fracture. However, intravenous bisphosphonate and denosumab are not recommended because of lack of evidence of fetal safety. Osteoporosis medications except calcium and vitamin D are not recommended for use during pregnancy. When bisphosphonates were used in pregnant rats in vivo, abnormal ossification and calcification of the offspring skeletal system were found at birth.[75] However, in pregnant women exposed to bisphosphonates before or during pregnancy, there were no differences in pregnancy outcomes or birth defects when compared to unexposed pregnant women.[76,77]

5) KQ5: How should response to treatment be monitored in patients with GIOP using physical measurements, imaging, and biochemical methods?

(1) Annual BMD and fracture risk assessment using FRAX are recommended in patients taking continuous GCs. The simple spine x-ray examination is recommended to evaluate vertebral fractures [Expert consensus/B].

(2) Regular follow-up is recommended to assess compliance with osteoporosis medication [Expert consensus/B].

(3) There is insufficient evidence for biochemical monitoring of treatment response in patients with GIOP [Expert consensus/I].

Annual BMD and fracture risk assessment using FRAX are recommended in patients taking continuous GCs [Expert consensus/B]. BMD is measured th the lumbar spine and hip by dual energy $\mathrm{X}$-ray absorptiometry. A simple spine $\mathrm{X}$-ray is recommended to evaluate vertebral fractures radiographically [Expert consensus/B]. Regular follow-up is recommended to assess compliance with osteo- porosis medications [Expert consensus/B]. There is insufficient evidence for biochemical monitoring of treatment response in patients with GIOP [Expert consensus/I].

\section{6) KQ6: Should discontinuation of osteoporosis} medication be considered if the fracture risk is reassessed to be low during GIOP treatment?

When GC treatment is discontinued in patients with GIOP and low fracture risk, discontinuation of osteoporosis medication may be considered. Discontinuation of osteoporosis medication should be individualized, taking into consideration the risk-benefit ratio [Expert consensus/B].

When GC treatment is discontinued in patients with GIOP and the result of fracture risk reassessment is low (low fracture risk), discontinuation of osteoporosis medication may be considered [Expert consensus/B]. Discontinuation of medication should be individualized, considering the risk-benefit ratio [Expert consensus/B]. For adults $\geq 40$ years of age, when GC treatment was discontinued, discontinuation of osteoporosis medication was considered if the patient had a follow-up BMD T-score >-2.5, a 10-year risk of major osteoporotic fracture $<10 \%$, or a 10 -year risk of hip fracture $<1 \%$ after FRAX adjustment for GCs dose. For adults $<40$ years of age, when GC medication was discontinued, discontinuation of osteoporosis medication was considered if there were no risk factors such as low BMD (Z score <-3.0), history of previous fracture, and low body weight. When fracture risk is moderate-to-high, osteoporosis medication should be continued even if GCs are discontinued.

7) KQ7: How should initial treatment failure be defined for GIOP?

If osteoporotic fractures occur more than 2 times after

(1) For adults $\geq 40$ years of age, initial treatment failure is defined as follows: Osteoporotic fractures occur more than 2 times after initiation of oral bisphosphonate treatment or osteoporotic fractures occur or there is significant $B M D$ reduction ( $\geq 10 \% /$ year) after 12 months of treatment initiation. Switching to another osteoporosis medication is recommended [Expert consensus/B]. 
(2) When fracture risk reassessment is moderate-to-high after 5 years of oral bisphosphonate treatment, active osteoporosis treatment is recommended [Expert consensus/B].

initiation of oral bisphosphonate treatment or osteoporotic fractures occur after 12 months of treatment initiation, or if there is significant BMD reduction ( $\geq 10 \% /$ year) at follow-up, this is defined as initial treatment failure. Switching to another osteoporosis medication is recommended [Expert consensus/B].

When fracture risk reassessment is moderate-to-high after oral bisphosphonate treatment for 5 years in adults $\geq 40$ years of age, active osteoporosis treatment is recommended [Expert consensus/B]. In this case, bisphosphonates could be used continuously without a drug holiday, and medications could be changed to intravenous bisphosphonate or other osteoporosis medications depending on the patient's drug compliance and treatment response.

\section{DISCUSSION}

The aim of developing this guideline was to promote effective treatment of GIOP by presenting standardized recommendations for prevention and treatment of GIOP for all clinicians treating patients who use or plan to use GCs. The primary implication of this guideline is that all clinicians treating patients with GCs should be aware of the risk of GIOP, identify those at high risk of fracture, and provide appropriate treatment. While osteoporosis treatment is currently given primarily to patients whose decreased bone mass was solely determined by BMD, this new guideline recommends that fracture risk should be assessed generally so that patients with moderate to high risk of fracture could receive osteoporosis treatment. Considering the pathophysiological characteristics of GIOP, it is clinically important to prevent the reduction of bone mass by glucocorticoids.

To develop this guideline, the KSBMR and the KCR jointly formed a development committee and a working committee with experts in the field. These committees used systematic literature searches and adapted previously-published guidelines, following guidelines for the development of CPGs by NECA. This new guideline includes rec- ommendations for the assessment and monitoring of fracture risk, as well as the treatment and prevention of fractures during the period of GC administration for adults $\geq 19$ years of age.

This guideline recommends the use of oral bisphosphonates as first line therapy for GIOP in adults $\geq 40$ years of age [I/A]. Other guidelines for osteoporosis primarily recommend the use of intravenous bisphosphonate, teriparatide, and denosumab for high-risk groups such as GIOP.[78] However, the major published clinical studies show that oral bisphosphonates have the highest evidence level when considering fracture reduction, safety, and cost.

This guideline has several limitations and many further studies are needed. First, since domestic clinical studies on GIOP have been scarce, this guideline was developed by adapting guidelines published in other countries. Unfortunately, the guidelines published in other countries also suffer from limited clinical and epidemiological data on $\mathrm{GIOP}$-induced fractures. Clinical trials assessing fracture as a primary outcome in patients taking GCs are especially needed. Notably, both GIOP and non-GIOP clinical trials show similar effects of osteoporosis medications on relative fracture risk. Therefore, results of non-GIOP clinical trials could be generalized to patients with GIOP. However, these estimates are not accurate in estimating clinical benefits from practical treatment. Second, this guideline accepts treatment criteria of FRAX, used in the USA. According to FRAX, osteoporosis treatment should be considered if the risk of major osteoporotic fractures over 10 years is $>10 \%$ or hip fracture risk over 10 years is $>1 \%$. If these treatment criteria are calculated in reverse by FRAX, we can estimate the range of BMD corresponding to treatment targets according to age. For example, FRAX would recommend treatment in the following patients: Korean women with a body mass index of $25 \mathrm{~kg} / \mathrm{m}^{2}$ when there is no other risk factor except taking GCs; and T-score of the hip BMD $\leq-2.0$ in all adults $\geq 40$ years of age, $\leq-1.5$ in adults $\geq 50$ years of age, $\leq-1.0$ in adults $\geq 60$ years of age, and any T-score in adults $\geq 80$ years of age. However, FRAX criteria specific to Koreans should be established to overcome the limitations of FRAX and to assess the risk of fracture more precisely. Third, there have been few studies of fractures in adults $<40$ years of age and, therefore, there are no means to assess fracture risk. Because of these limitations, the levels of evidence of most of the recommenda- 
tions in these guidelines were moderate (II) or expert consensus.

This guideline recommends that calcium and vitamin D could be administered to patients with GIOP, as it is to postmenopausal osteoporosis patients, but the evidence is not sufficient. Although there is a concern for cardiovascular risk due to calcium and vitamin D supplementation, adequate calcium intake might be more important because GCs increase urinary calcium excretion in patients taking $\mathrm{GCs}$. Hence, it is necessary to investigate the appropriate calcium and vitamin D supplementation for patients taking GCs. Additional studies in patients taking GCs are needed to investigate the differences of fracture risk according to age and gender, the role of the simple spine $X$ ray to assess fracture risk, fetal safety of osteoporosis medication in women with childbearing potential, and the effects of pharmacological treatment in children.

In Korea, osteoporosis medication is recognized as an insurance benefit only when the T-score is $\leq-2.5$ in BMD testing or when osteoporotic fracture is detected at the time of radiography. However, as described above, because the risk of $\mathrm{GC}$-induced fracture increases before a significant reduction in bone mass occurs, [3] many patients' fracture risk could be underestimated if the decision to treat GIOP is made solely from the results of BMD. Therefore, gradual institutional improvement is needed to expand the insurance coverage of osteoporosis medications to patients at high risk of fracture, such as those taking GCs long-term and previous fracture history. Additionally, an efficient quality index should be developed to assess the effectiveness of this guideline in the prevention and treatment of GIOP.

\section{CONCLUSIONS}

In conclusion, GIOP is a problem that all clinicians should be interested in, and patients should also be aware of the risks. Clinicians should evaluate the risk of fracture for all patients taking GCs and actively prevent reduction of bone mass.

\section{ACKNOWLEDGMENTS}

The Korean Society for Bone and Mineral Research and the Korean College of Rheumatology financially supported the development of this guideline. However, these organi- zations did not affect the content of this guideline.

\section{CONFLICT OF INTEREST}

Yoon-Kyung Sung has received financial support for clinical research sponsored by Pfizer within the last 2 years. Dong Ah Park has participated in the development of headache clinical practical guidelines for methodology consultation. The other authors declare no conflict of interest. If a committee member receives research funding from a company, that member does not participate in discussions or votes concerning that company's drug.

\section{SUPPLEMENTARY MATERIALS}

Supplementary Appendix 1-8. Data files are available from https://doi.org/10.11005/jbm.2018.25.4.195.

\section{REFERENCES}

1. Saag KG, Koehnke R, Caldwell JR, et al. Low dose long-term corticosteroid therapy in rheumatoid arthritis: an analysis of serious adverse events. Am J Med 1994;96:115-23.

2. Lane NE, Lukert B. The science and therapy of glucocorticoid-induced bone loss. Endocrinol Metab Clin North Am 1998;27:465-83.

3. Van Staa TP, Laan RF, Barton IP, et al. Bone density threshold and other predictors of vertebral fracture in patients receiving oral glucocorticoid therapy. Arthritis Rheum 2003;48:3224-9.

4. Steinbuch M, Youket TE, Cohen S. Oral glucocorticoid use is associated with an increased risk of fracture. Osteoporos Int 2004;15:323-8.

5. Angeli A, Guglielmi G, Dovio A, et al. High prevalence of asymptomatic vertebral fractures in post-menopausal women receiving chronic glucocorticoid therapy: a cross-sectional outpatient study. Bone 2006;39:253-9.

6. Feldstein AC, Elmer PJ, Nichols GA, et al. Practice patterns in patients at risk for glucocorticoid-induced osteoporosis. Osteoporos Int 2005;16:2168-74.

7. Salerno A, Hermann R. Efficacy and safety of steroid use for postoperative pain relief. Update and review of the medical literature. J Bone Joint Surg Am 2006;88:1361-72.

8. Fardet L, Petersen I, Nazareth I. Monitoring of patients on long-term glucocorticoid therapy: a population-based co- 
hort study. Medicine (Baltimore) 2015;94:e647.

9. Van Staa TP, Leufkens HG, Abenhaim L, et al. Use of oral corticosteroids in the United Kingdom. QJM 2000;93:10511.

10. Van Staa TP, Leufkens HG, Cooper C. The epidemiology of corticosteroid-induced osteoporosis: a meta-analysis. Osteoporos Int 2002;13:777-87.

11. LoCascio V, Bonucci $E$, Imbimbo $B$, et al. Bone loss in response to long-term glucocorticoid therapy. Bone Miner 1990;8:39-51.

12. Kim D, Cho SK, Park B, et al. Glucocorticoids are associated with an increased risk for vertebral fracture in patients with rheumatoid arthritis. J Rheumatol 2018;45:612-20.

13. Weinstein RS. True strength. J Bone Miner Res 2000;15:621-5.

14. Leslie WD. The importance of spectrum bias on bone density monitoring in clinical practice. Bone 2006;39:361-8.

15. Seeman E, Delmas PD. Bone quality--the material and structural basis of bone strength and fragility. N Engl J Med 2006; 354:2250-61.

16. Buckley L, Guyatt G, Fink HA, et al. 2017 American college of rheumatology guideline for the prevention and treatment of glucocorticoid-induced osteoporosis. Arthritis Care Res (Hoboken) 2017;69:1095-110.

17. Van Staa TP, Geusens P, Pols HA, et al. A simple score for estimating the long-term risk of fracture in patients using oral glucocorticoids. QJM 2005;98:191-8.

18. Hall GM, Spector TD, Griffin AJ, et al. The effect of rheumatoid arthritis and steroid therapy on bone density in postmenopausal women. Arthritis Rheum 1993;36:1510-6.

19. Laan RF, van Riel PL, van de Putte LB, et al. Low-dose prednisone induces rapid reversible axial bone loss in patients with rheumatoid arthritis. A randomized, controlled study. Ann Intern Med 1993;119:963-8.

20. Kim SY, Jee SM, Lee SJ, et al. Guidance for development of clinical practice guidelines. ver 1.0. Seoul: National Evidence-based Healthcare Collaborating Agency; 2011.

21. Grossman JM, Gordon R, Ranganath VK, et al. American college of rheumatology 2010 recommendations for the prevention and treatment of glucocorticoid-induced osteoporosis. Arthritis Care Res (Hoboken) 2010;62:1515-26.

22. Lekamwasam S, Adachi JD, Agnusdei D, et al. A framework for the development of guidelines for the management of glucocorticoid-induced osteoporosis. Osteoporos Int 2012; 23:2257-76.

23. Papaioannou A, Morin S, Cheung AM, et al. 2010 clinical practice guidelines for the diagnosis and management of osteoporosis in Canada: summary. CMAJ 2010;182:186473.

24. Briot K, Cortet B, Roux C, et al. 2014 update of recommendations on the prevention and treatment of glucocorticoid-induced osteoporosis. Joint Bone Spine 2014;81:493501.

25. Pereira RM, Carvalho JF, Paula AP, et al. Guidelines for the prevention and treatment of glucocorticoid-induced osteoporosis. Rev Bras Reumatol 2012;52:580-93.

26. Suzuki Y, Nawata H, Soen S, et al. Guidelines on the management and treatment of glucocorticoid-induced osteoporosis of the Japanese Society for Bone and Mineral Research: 2014 update. J Bone Miner Metab 2014;32:337-50.

27. Rossini M, Adami S, Bertoldo F, et al. Guidelines for the diagnosis, prevention and management of osteoporosis. Reumatismo 2016;68:1-39.

28. Brouwers MC, Kho ME, Browman GP, et al. AGREE II: advancing guideline development, reporting and evaluation in health care. J Clin Epidemiol 2010;63:1308-11.

29. Compston J, Cooper A, Cooper C, et al. UK clinical guideline for the prevention and treatment of osteoporosis. Arch Osteoporos 2017;12:43.

30. Kanis JA, Johansson H, Oden A, et al. Guidance for the adjustment of FRAX according to the dose of glucocorticoids. Osteoporos Int 2011;22:809-16.

31. Kaji H, Yamauchi M, Chihara K, et al. Glucocorticoid excess affects cortical bone geometry in premenopausal, but not postmenopausal, women. Calcif Tissue Int 2008;82:18290.

32. Fassio $A$, Idolazzi $L$, Jaber $M A$, et al. The negative bone effects of the disease and of chronic corticosteroid treatment in premenopausal women affected by rheumatoid arthritis. Reumatismo 2016;68:65-71.

33. Canalis E, Mazziotti G, Giustina A, et al. Glucocorticoid-induced osteoporosis: pathophysiology and therapy. Osteoporos Int 2007;18:1319-28.

34. Sambrook P, Birmingham J, Kelly $P$, et al. Prevention of corticosteroid osteoporosis. A comparison of calcium, calcitriol, and calcitonin. N Engl J Med 1993;328:1747-52.

35. Boutsen $Y$, Jamart J, Esselinckx W, et al. Primary prevention of glucocorticoid-induced osteoporosis with intravenous pamidronate and calcium: a prospective controlled 1-year study comparing a single infusion, an infusion given once every 3 months, and calcium alone. J Bone Miner 
Res 2001;16:104-12.

36. Adachi JD, Bensen WG, Bianchi F, et al. Vitamin D and calcium in the prevention of corticosteroid induced osteoporosis: a 3 year followup. J Rheumatol 1996;23:995-1000.

37. Buckley LM, Leib ES, Cartularo KS, et al. Calcium and vitamin D3 supplementation prevents bone loss in the spine secondary to low-dose corticosteroids in patients with rheumatoid arthritis. A randomized, double-blind, placebo-controlled trial. Ann Intern Med 1996;125:961-8.

38. Braun JJ, Birkenhäger-Frenkel DH, Rietveld AH, et al. Influence of 1 alpha- $(\mathrm{OH}) \mathrm{D} 3$ administration on bone and bone mineral metabolism in patients on chronic glucocorticoid treatment; a double blind controlled study. Clin Endocrinol (Oxf) 1983;19:265-73.

39. Reginster JY, Kuntz D, Verdickt W, et al. Prophylactic use of alfacalcidol in corticosteroid-induced osteoporosis. Osteoporos Int 1999;9:75-81.

40. Okada Y, Nawata M, Nakayamada S, et al. Alendronate protects premenopausal women from bone loss and fracture associated with high-dose glucocorticoid therapy. J Rheumatol 2008;35:2249-54.

41. Saag KG, Emkey R, Schnitzer TJ, et al. Alendronate for the prevention and treatment of glucocorticoid-induced osteoporosis. Glucocorticoid-Induced Osteoporosis Intervention Study Group. N Engl J Med 1998;339:292-9.

42. Adachi JD, Saag KG, Delmas PD, et al. Two-year effects of alendronate on bone mineral density and vertebral fracture in patients receiving glucocorticoids: a randomized, double-blind, placebo-controlled extension trial. Arthritis Rheum 2001;44:202-11.

43. Lems WF, Lodder MC, Lips P, et al. Positive effect of alendronate on bone mineral density and markers of bone turnover in patients with rheumatoid arthritis on chronic treatment with low-dose prednisone: a randomized, double-blind, placebo-controlled trial. Osteoporos Int 2006; 17:716-23.

44. Stoch SA, Saag KG, Greenwald M, et al. Once-weekly oral alendronate $70 \mathrm{mg}$ in patients with glucocorticoid-induced bone loss: a 12-month randomized, placebo-controlled clinical trial. J Rheumatol 2009;36:1705-14.

45. Tee SI, Yosipovitch G, Chan YC, et al. Prevention of glucocorticoid-induced osteoporosis in immunobullous diseases with alendronate: a randomized, double-blind, placebo-controlled study. Arch Dermatol 2012;148:307-14.

46. Wallach S, Cohen S, Reid DM, et al. Effects of risedronate treatment on bone density and vertebral fracture in patients on corticosteroid therapy. Calcif Tissue Int 2000;67: 277-85.

47. Yamada S, Takagi H, Tsuchiya H, et al. Comparative studies on effect of risedronate and alfacalcidol against glucocorticoid-induced osteoporosis in rheumatoid arthritic patients. Yakugaku Zasshi 2007;127:1491-6.

48. Cohen S, Levy RM, Keller M, et al. Risedronate therapy prevents corticosteroid-induced bone loss: a twelve-month, multicenter, randomized, double-blind, placebo-controlled, parallel-group study. Arthritis Rheum 1999;42:2309-18.

49. Reid DM, Devogelaer JP, Saag K, et al. Zoledronic acid and risedronate in the prevention and treatment of glucocorticoid-induced osteoporosis (HORIZON): a multicentre, double-blind, double-dummy, randomised controlled trial. Lancet 2009;373:1253-63.

50. Langdahl BL, Marin F, Shane E, et al. Teriparatide versus alendronate for treating glucocorticoid-induced osteoporosis: an analysis by gender and menopausal status. Osteoporos Int 2009;20:2095-104.

51. Saag KG, Wagman RB, Geusens P, et al. Denosumab versus risedronate in glucocorticoid-induced osteoporosis: a multicentre, randomised, double-blind, active-controlled, double-dummy, non-inferiority study. Lancet Diabetes Endocrinol 2018;6:445-54.

52. Candelas G, Martinez-Lopez JA, Rosario MP, et al. Calcium supplementation and kidney stone risk in osteoporosis: a systematic literature review. Clin Exp Rheumatol 2012;30: 954-61.

53. Lewis JR, Radavelli-Bagatini S, Rejnmark L, et al. The effects of calcium supplementation on verified coronary heart disease hospitalization and death in postmenopausal women: a collaborative meta-analysis of randomized controlled trials. J Bone Miner Res 2015;30:165-75.

54. de Nijs RN, Jacobs JW, Lems WF, et al. Alendronate or alfacalcidol in glucocorticoid-induced osteoporosis. N Engl J Med 2006;355:675-84.

55. Yilmaz L, Ozoran K, Gündüz $\mathrm{OH}$, et al. Alendronate in rheumatoid arthritis patients treated with methotrexate and glucocorticoids. Rheumatol Int 2001;20:65-9.

56. Eastell R, Devogelaer JP, Peel NF, et al. Prevention of bone loss with risedronate in glucocorticoid-treated rheumatoid arthritis patients. Osteoporos Int 2000;11:331-7.

57. Reid DM, Adami S, Devogelaer JP, et al. Risedronate increases bone density and reduces vertebral fracture risk with- 
in one year in men on corticosteroid therapy. Calcif Tissue Int 2001;69:242-7.

58. Reid DM, Hughes RA, Laan RF, et al. Efficacy and safety of daily risedronate in the treatment of corticosteroid-induced osteoporosis in men and women: a randomized trial. European Corticosteroid-Induced Osteoporosis Treatment Study. J Bone Miner Res 2000;15:1006-13.

59. Hakala $M$, Kröger $H$, Valleala $H$, et al. Once-monthly oral ibandronate provides significant improvement in bone mineral density in postmenopausal women treated with glucocorticoids for inflammatory rheumatic diseases: a 12-month, randomized, double-blind, placebo-controlled trial. Scand J Rheumatol 2012;41:260-6.

60. Sambrook PN, Roux C, Devogelaer JP, et al. Bisphosphonates and glucocorticoid osteoporosis in men: results of a randomized controlled trial comparing zoledronic acid with risedronate. Bone 2012;50:289-95.

61. Durie BG, Katz M, Crowley J. Osteonecrosis of the jaw and bisphosphonates. N Engl J Med 2005;353:99-102.

62. Lazarovici TS, Yahalom R, Taicher S, et al. Bisphosphonaterelated osteonecrosis of the jaws: a single-center study of 101 patients. J Oral Maxillofac Surg 2009;67:850-5.

63. Woo SB, Hellstein JW, Kalmar JR. Narrative [corrected] review: bisphosphonates and osteonecrosis of the jaws. Ann Intern Med 2006;144:753-61.

64. Giusti A, Hamdy NA, Dekkers OM, et al. Atypical fractures and bisphosphonate therapy: a cohort study of patients with femoral fracture with radiographic adjudication of fracture site and features. Bone 2011;48:966-71.

65. Edwards MH, McCrae FC, Young-Min SA. Alendronate-related femoral diaphysis fracture--what should be done to predict and prevent subsequent fracture of the contralateral side? Osteoporos Int 2010;21:701-3.

66. Goh SK, Yang KY, Koh JS, et al. Subtrochanteric insufficiency fractures in patients on alendronate therapy: a caution. J Bone Joint Surg Br 2007;89:349-53.

67. Ing-Lorenzini K, Desmeules J, Plachta O, et al. Low-energy femoral fractures associated with the long-term use of bisphosphonates: a case series from a Swiss university hospital. Drug Saf 2009;32:775-85.

68. Kwek EB, Goh SK, Koh JS, et al. An emerging pattern of subtrochanteric stress fractures: a long-term complication of alendronate therapy? Injury 2008;39:224-31.

69. Shane E, Burr D, Abrahamsen B, et al. Atypical subtrochanteric and diaphyseal femoral fractures: second report of a task force of the American Society for Bone and Mineral Research. J Bone Miner Res 2014;29:1-23.

70. Lane NE, Sanchez S, Modin GW, et al. Parathyroid hormone treatment can reverse corticosteroid-induced osteoporosis. Results of a randomized controlled clinical trial. J Clin Invest 1998;102:1627-33.

71. Saag KG, Zanchetta JR, Devogelaer JP, et al. Effects of teriparatide versus alendronate for treating glucocorticoid-induced osteoporosis: thirty-six-month results of a randomized, double-blind, controlled trial. Arthritis Rheum 2009; 60:3346-55

72. Saag KG, Shane E, Boonen S, et al. Teriparatide or alendronate in glucocorticoid-induced osteoporosis. N Engl J Med 2007;357:2028-39.

73. Dore RK, Cohen SB, Lane NE, et al. Effects of denosumab on bone mineral density and bone turnover in patients with rheumatoid arthritis receiving concurrent glucocorticoids or bisphosphonates. Ann Rheum Dis 2010;69:872-5.

74. Mok CC, Ying KY, To CH, et al. Raloxifene for prevention of glucocorticoid-induced bone loss: a 12-month randomised double-blinded placebo-controlled trial. Ann Rheum Dis 2011;70:778-84.

75. Patlas N, Golomb G, Yaffe P, et al. Transplacental effects of bisphosphonates on fetal skeletal ossification and mineralization in rats. Teratology 1999;60:68-73.

76. Levy S, Fayez I, Taguchi N, et al. Pregnancy outcome following in utero exposure to bisphosphonates. Bone 2009; 44:428-30.

77. Ornoy A, Wajnberg R, Diav-Citrin O. The outcome of pregnancy following pre-pregnancy or early pregnancy alendronate treatment. Reprod Toxicol 2006;22:578-9.

78. Camacho PM, Petak SM, Binkley N, et al. American association of clinical endocrinologists and American college of endocrinology clinical practice guidelines for the diagnosis and treatment of postmenopausal osteoporosis-2016. Endocr Pract 2016;22:1-42. 
